\title{
RADIAL ARTERY: ANATOMICAL VARIATIONS AT WRIST AND CLINICAL SIGNIFICANCE
}

\section{Raviprasanna $\mathrm{K} \mathrm{H}^{1}$, Aditya Krishna Das ${ }^{* 2}$, Anand L Kulkarni ${ }^{3}$.}

${ }^{1}$ Associate Professor, Department of Anatomy, Mamata Medical College, Rotary Nagar, Khammam, Telangana, India.

${ }^{* 2}$ Associate Professor, Department of Anatomy, Sree Narayana Institute of Medical Sciences, Chalakka, North Kuthiyathodu (PO), Ernakulam, Kerala, India.

${ }^{3}$ Professor and Head, Department of Anatomy, Sree Narayana Institute of Medical Sciences, Chalakka, North Kuthiyathodu (PO), Ernakulam, Kerala, India.

\section{ABSTRACT}

Background: Knowledge regarding the course and termination of the radial artery before harvesting it for coronary artery bypass graft surgery (CABGS) is important. The brachial artery terminates at the neck of radius into radial and ulnar arteries.

Purpose of the study: To know the various patterns of anomalous division ofthe radial artery.

Methods: The study included 50 upper limb specimens from the Department of Anatomy, Sree Narayana Institute of Medical Sciences, Ernakulam. The specimens were fixed with $10 \%$ formalin solution and the radial artery was exposed from its origin till termination and observations were noted down.

Results: The present study revealed that, radial artery usually was arising from brachial artery at the level of neck of radius. The variants observed included high bifurcation of brachial artery, division of radial artery into palmar and dorsal branches in the forearm and anomalous course of radial artery in the region of anatomical snuff box.

Conclusion: The present study has revealed the anomalous division and course of radial artery around the wrist and anatomical snuff box and the knowledge of such anomalous course is important for diagnostic, interventional and surgical procedures.

KEY WORDS: Radial artery, Dorsal branch, Palmar branch, Superficial palmar arch, Anatomical snuff box.

Address for Correspondence: Dr. Aditya Krishna Das, Associate Professor, Department of Anatomy, Sree Narayana Institute of Medical Sciences, Chalakka,North Kuthiyathodu (PO), Ernakulam, Kerala-683594, India. Phone:+91-8589851223. E-Mail: adityakdas@gmail.com

Access this Article online

Quick Response code

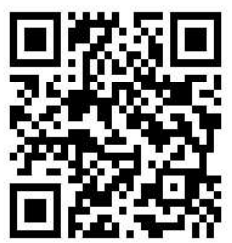

DOI: $10.16965 /$ ijar.2019.213

Journal Information

International Journal of Anatomy and Research

\begin{tabular}{|c|c|}
$\begin{array}{c}\text { ICV for } 2016 \\
\mathbf{9 0 . 3 0}\end{array}$ & $\begin{array}{c}\text { ISSN (E) 2321-4287 I ISSN (P) 2321-8967 } \\
\text { https://www.ijmhr.org/ijar.htm } \\
\text { DOI-Prefix: https://dx.doi.org/10.16965/ijar }\end{array} \quad$ (cc) B广-Mi-BA
\end{tabular}

Article Information

Received: 29 Apr 2019

Peer Review: 30 Apr 2019

Revised: None
Accepted: 10 Jun 2019

Published (O): 05 Jul 2019

Published (P): 05 Jul 2019

\section{INTRODUCTION}

The radial artery is one of the terminal branches of brachial artery in the cubital fossa. Brachial artery at the neck of radius, divides into radial and ulnar arteries. In the proximal one third of the forearm radial artery is medial to biceps brachii tendon and passes deep to the muscular belly of brachioradialis, In the middle one-third it is medial to the brachioradialis tendon, In the distal forearm, the radial artery can be located using the flexor carpi radialis as a landmark and at the wrist, the artery winds dorsally deep to the tendons of the abductor pollicis longus, extensor pollicis longus and 
extensor pollicis brevis to cross through the anatomical snuff box. It then leaves the dorsal surface of the wrist through a triangular gap between the 2 heads of first dorsal interosseous muscle, where the artery is crossed superficially by the extensor pollicis longus tendon. The radial artery accompanied by a pair of venae comitantes lies superficially covered by skin \& superficial fascia in major portions except at the proximal part where it is overlapped by brachioradialis muscle [1]. Variations in the origin of radial artery are common, with incidence of $15 \%[2,3]$ and rare with respect to its course where incidence is $0.52 \%$ [4].

Manners-Smith [5] classified the variations in the course of radial artery into two classes, according to the relation of radial artery with the tendons forming the anatomical snuff box. In the first class, the radial artery is single and is entirely superficial to the tendons of the anatomical snuff box, also known as the superficial dorsal artery of the forearm [6]. In the second class, the radial artery divides into superficial and deep branches, also documented as partial duplication of the radial artery [4] or duplication of the radial artery [7].

The knowledge regarding anatomical variants of radial artery near wrist would beuseful while harvesting radial artery for coronary artery bypass grafting.

\section{METHODS}

50 previously dissected upper limb specimens used in this study which were used to educate medical undergraduate students at Sree Narayana Institute of Medical Sciences, Ernakulam. The specimens were fixed with $10 \%$ neutral buffered formalin solution. The radial artery was exposed and traced from its origin to termination by cleaning the connective tissue around it. The course, branches and variants of the radial artery were observed and measurements were taken in the specimens showing anomalous course of radial artery with the help of vernier calipers. The styloid process of radius was taken as the point of landmark for measuring the early division of radial artery into palmar and dorsal branches.

\section{RESULTS}

The observations and measurements noted down in the present study are represented in the form of tables numbered from 1 to $3 . \ln 2 \%$ of the specimens, the radial artery was arising $5.6 \mathrm{cms}$ proximal to the neck of the radius [Table-1]. 5 specimens $(10 \%)$ revealed that the radial artery divided into palmar and dorsal branches proximal to the styloid process of radius in the distal half of forearm[Table -2]. The origin of palmar branch12.2 cms proximal to radial styloid process, which continued superficial to flexor retinaculum and thenar muscles in the palmto form part of incomplete superficial palmar arch and supplied lateral two and half fingers was observed in $2 \%$ of the specimens [Figure 1]. The radial artery division into palmar and dorsal branches $4.7 \mathrm{cms}$ proximal to radial styloid process was observed in $2 \%$ of the specimens [Figure 2] where palmar branch bifurcated into superficial and deep branches. Superficial branch continued into palm as superficial palmar branch of radial artery to form complete superficial palmar arch in which the same arch supplied radial side of index finger and both sides of thumb. The deep branch traversed through the anatomical snuff box to terminate in dorsal carpal arch. In $4 \%$ of the specimens, the larger dorsal branchfrom radial artery had superficial course over the tendons of abductor pollicis longus, extensor pollicis brevis and extensor pollicis longus which formed boundaries of anatomical snuff box. The dorsal branch of radial artery later pierced through first interdigital cleft to enter palm [Table - 3]. The dorsal branch of radial artery gave first dorsal metacarpal artery and arteria princeps pollicis which supplied adjacent sides of thumb and lateral side of index finger in $2 \%$ of the specimens [Figure 3]. Terminal part of the dorsal branch of radial artery continued into the palm to form deep palmar arch.

Fig. 1: Course of palmar and dorsal branches of radial artery and incomplete superficial palmar arch.

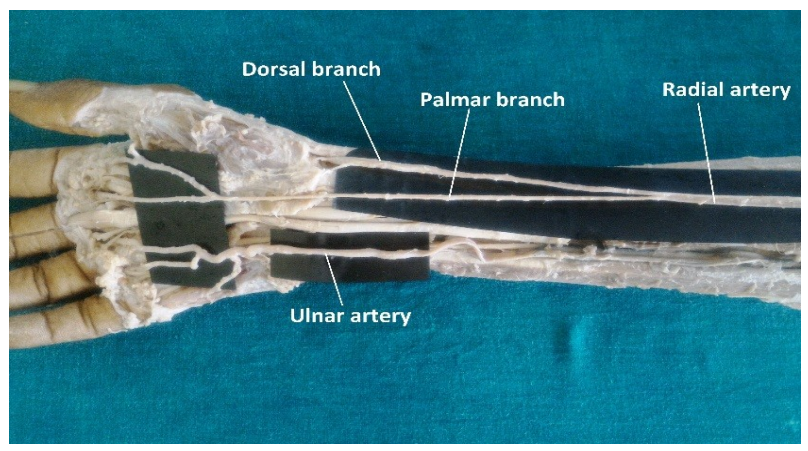


Fig. 2: Superficial radial artery in the lower third of forearm.

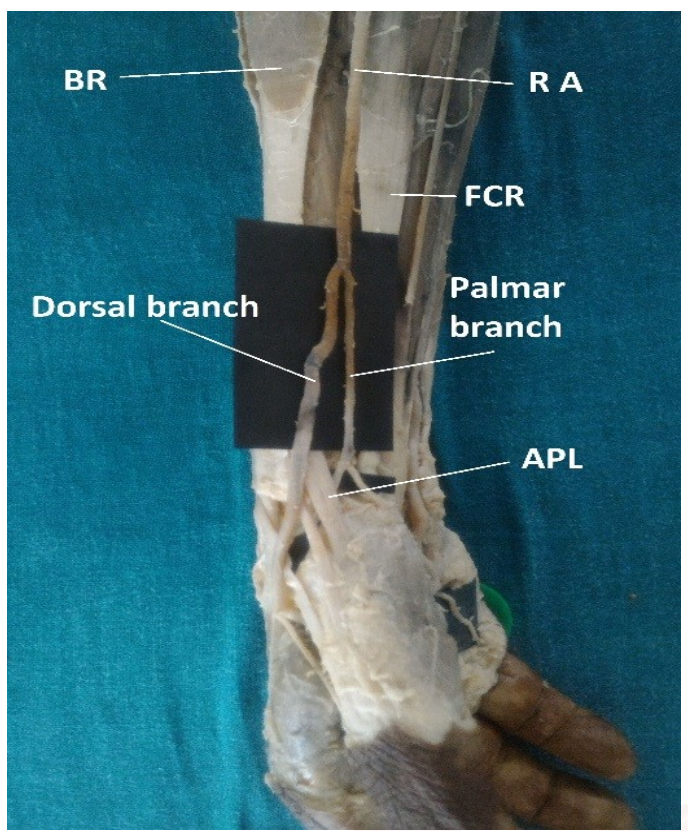

Fig. 3: Superficial radial artery and its termination.

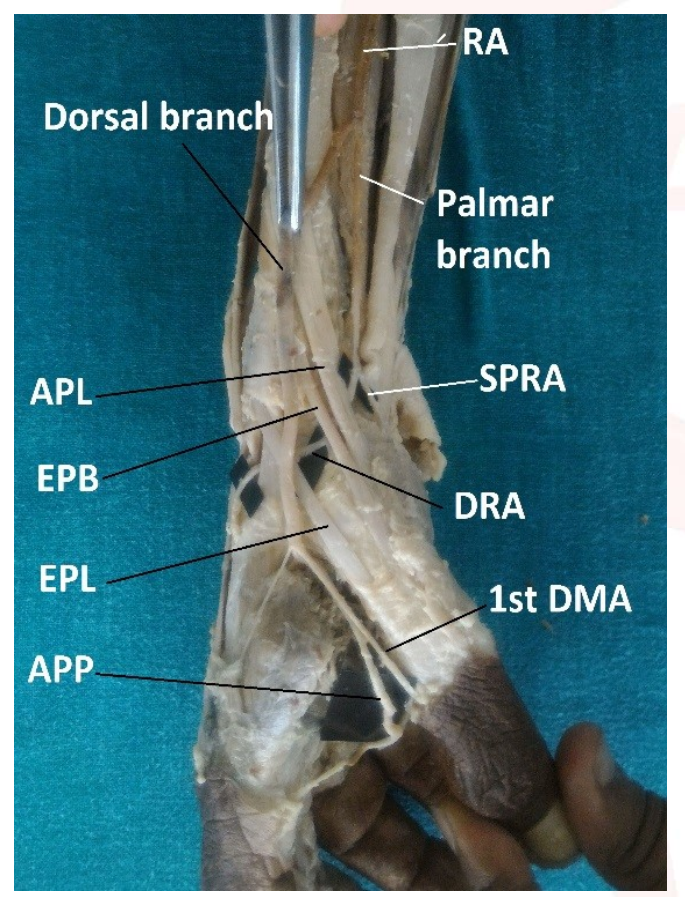

RA - Radial artery, FCR - Flexor carpi radialis, $B R$ - Brachioradialis, APL - Abductor pollicis longus, SPRA - Superficial palmar branch of radial artery, DRA - Deep branch of radial artery, $1^{\text {st }}$ DMA - Dorsal metacarpal artery, EPB - Extensor pollicis brevis, EPL - Extensor pollicis longus, APP - Arteria princeps pollicis.

Table 1: Origin of radial artery inrelation to Interepicondylar line of Humerus.

\begin{tabular}{|l|c|}
\hline \multicolumn{1}{|c|}{ Radial artery } & $\begin{array}{c}\text { Number of } \\
\text { specimen }\end{array}$ \\
\hline Origin distal to Interepicondylar line of humerus (IEL) & 49 \\
\hline Origin proximal to Interepicondylar line of humerus (IEL) & 1 \\
\hline Total & 50 \\
\hline
\end{tabular}

Int J Anat Res 2019, 7(3.1):6740-43. ISSN 2321-4287
Table 2: Division of radial artery into palmar and dorsal branches in the forearm.

\begin{tabular}{|l|c|c|c|c|}
\hline \multicolumn{1}{|c|}{ Range } & Right & $\%$ & Left & $\%$ \\
\hline At styloid process & 21 & 42 & 24 & 48 \\
\hline$<3 \mathrm{~cm}$ (In the forearm) & 1 & 2 & 1 & 2 \\
\hline$>3 \mathrm{~cm}$ (In the forearm) & 3 & 6 & Nil & 0 \\
\hline
\end{tabular}

Table 3: Course of radial artery near the anatomical snuff box.

\begin{tabular}{|l|c|c|c|c|}
\hline \multicolumn{1}{|c|}{ Relations } & Right & $\%$ & Left & $\%$ \\
\hline Within the anatomical snuff box & 23 & 46 & 25 & 50 \\
\hline Superficial to anatomical snuff box & 2 & 4 & Nil & - \\
\hline Total & 25 & 50 & 25 & 50 \\
\hline
\end{tabular}

\section{DISCUSSION}

Superficial radial artery is a rare variant $\&$ is defined as a radial artery of normal origin at neck of radius but at the wrist crosses superficial to tendons forming boundaries of anatomical snuff box [4] with incidence of $0.52 \%$ to $1 \%$. Studies reveal that this variant of artery is usually unilateral [2]. If present, a superficial radial artery usually originates at the distal third of the forearm [2, 4, 8 and 9], less commonly from the proximal third of the forearm $[10,11]$ and in a single case it arose above the elbow level [2]. In the present study, superficial radial artery was observed in 2 specimens (4\%). The superficial radial artery is usually larger than the deep branch which usually has normal course through the anatomical snuff box[9, 11 and 12]. The existence of superficial radial artery which passes superficially along the course of cephalic vein implies the possibility of absence of radial pulse at wrist which is the common site to feel the peripheral pulse by clinicians. This superificial course of radial artery over anatomical snuff box may produce problemsin intravenous cannulation during operation monitoring or hospitalization[13] and pose a hazard for inadvertent intra-arterial drug administration owing to its proximity to the cephalic vein [6].

Accidental cannulation or injection of the superficial radial artery requires immediate surgical intervention to avoid vascular compromise secondary to repetitive abuse[14]. Radial artery is commonly used for coronary artery bypass grafting. Before harvesting the radial artery, the cardiovascular surgeons should check for the course of radial artery to avoid further 
complications. Anatomical variants of blood vessels usually occur due to anomalies during embryonic development. In primates the radial artery divides into a volar branch, which in thehuman is represented by a radiopalmar branch, and a dorsal branch, which is represented by the normal radial artery, which further divides into superficial and deep branches in relation to the tendons in the anatomical snuff box [5]. Radial artery which ends by forming deep palmar arch plays key role in tendon transplantation. If orthopedic surgeons miss the superficial course of radial artery in dorsum of hand during tendon transplantation, this may lead to hemorrhage and further complications [15].

\section{CONCLUSION}

Feeling the pulse of the radial arterya gainst the lower end of radius by physicians is clinically important as its one of the common sites to feel peripheral arterial pulse. Radial artery is also one of the commonest vessels harvested for coronary bypass graft surgery. Anomalous course of arteries is common and some have greater clinical significance and some are of academic interest. The superficial radial artery which has superficial course in the roof of anatomical snuff box can be mistaken for cephalic vein and accidental injection of drugs in the artery might cause secondary complications. The absence of pulse at the wrist on radial side can be explained by the anomalous course of radial artery. The knowledge of such anomalous course would be important for diagnostic, interventional and surgical procedures.Even though, diagnostic arterial studies like arteriogram or MRA will help preoperatively assess any vascular anomalies, it is important for a healthcare personal to follow a simple and inexpensive tool of palpation for the presence of a radial pulse before cannulation. A further extensive study on the course of radial artery near distal forearm and over the anatomical snuff box can put further insight on this topic.

\section{Conflicts of Interests: None}

\section{REFERENCES}

[1]. Standring $S$, Ellis $H$, Healy JC, Johnson D, Williams A, Collins P, Wigley C (2005). Gray's Anatomy, 39th Ed. Elsevier Churchill Livingstone, New York, pp 883; 925-929.

[2]. McCormack LJ, Cauldwell EW, Anson J. Brachial and antebrachial arterial patterns. Surg Gyne and Obs 1953;96:43-54.

[3]. Tountas CP, Bergman RA (1993). Anatomic variations of the upper extremity. Churchill Livingstone, pp 205- 210.

[4]. Rodriguez-Niedenfuhr M, Vazquez T, Nearn L, Ferreira B, Parkin I, Sanudo JR. Variations of the arterial pattern in the upper limb revisited: a morphological and statistical study, with a review of the literature. J Anat, 2001;199:547-566.

[5]. Manners-Smith T. The limb arteries of primates. JAnat Physiol, 1911;45:23-64.

[6]. Morris G, Rowe M, Delacure D. Superficial dorsal artery of the forearm: Case report and review of the literature. Ann Plast Surg, 2005;55:538-541.

[7]. Bumbasirevic M, Lesic A, Filipovic B. Duplication of radial artery in the radial forearm flap. Clin Anat, 2005;18:305-307.

[8]. Heden P, Gylbert L (1990). Anomaly of the radial artery encountered during elevation of the radial forearm flap. J Reconstr Microsurg, 1990;6:139-141.

[9]. Woods SJ, Abrahams PH, Sanudo JR, Ferreira BJ. Bilateral superficial radial artery at the wrist associated with a radial origin of a unilateral median artery. J Anat, 1997;189: 691-693.

[10]. Martin-Granizo R, Gomez F, Sanchez-Cuellar A. An unusual anomaly of the radial artery with potential significance to the forearm free flap. Case report. J Cran Maxillofacial Surg, 2002;30:189-191.

[11]. Sasaki K, Nozaki M, Aiba H, Isono N. A rare variant of the radial artery: Clinical considerations in raising a radial forearm flap. Br J Plast Surg, 1999;53:45447.

[12]. Bumbasirevic M, Lesic A, Filipovic B. Duplication of radial artery in the radial forearm flap. Clin Anat, 2005;18:305-307.

[13]. Diz JC, Ares X, Tarrazo AM, Alvarez J, Meanos ER. Bilateral superficial radial artery at the wrist. Acta Anaes Scand, 1998;42:1020.

[14]. Brown MJ, Edstrom LE, Zienowicz RJ. A symptomatic radial artery anomaly and its surgical treatment.J Hand Surg, 1999;24A:178-181.

[15]. Krishnaveni C, Roopa Kulkarni. Variation of radial artery in the left hand- a case report. Anatomica Karnataka, 2011;5(3):61-65.

How to cite this article:

Raviprasanna K H, Aditya Krishna Das, Anand L Kulkarni. RADIAL ARTERY: ANATOMICAL VARIATIONS AT WRIST AND CLINICAL SIGNIFICANCE. Int J Anat Res 2019;7(3.1):67406743. DOI: $10.16965 /$ ijar.2019.213 